\title{
Weak fatigue notch sensitivity in a biomedical titanium alloy exhibiting nonlinear elasticity
}

\author{
Jinrui Zhang ${ }^{1,2}$, Syed A. A. Shah ${ }^{1}$, Yulin $\mathrm{Hao}^{1 *}$, Shujun $\mathrm{Li}^{1}$ and Rui Yang ${ }^{1}$
}

\begin{abstract}
It is well known that metallic materials exhibit worse fatigue damage tolerance as they behave stronger in strength and softer in modulus. This raises concern on the long term safety of the recently developed biomechanical compatible titanium alloys with high strength and low modulus. Here we demonstrate via a model alloy, Ti-24Nb-4Zr$8 \mathrm{Sn}$ in weight percent, that this group of multifunctional titanium alloys possessing nonlinear elastic deformation behavior is tolerant in fatigue notch damage. The results reveal that the alloy has a high strength-to-modulus $(\sigma / E)$ ratio reaching $2 \%$ but its fatigue notch sensitivity $(q)$ is low, which decreases linearly from 0.45 to 0.25 as stress concentration factor increases from 2 to 4 . This exceeds significantly the typical relationship between $\sigma / E$ and $q$ of other metallic materials exhibiting linear elasticity. Furthermore, fatigue damage is characterized by an extremely deflected mountain-shape fracture surface, resulting in much longer and more tortuous crack growth path as compared to these linear elastic materials. The above phenomena can be explained by the nonlinear elasticity and its induced stress relief at the notch root in an adaptive manner of higher stress stronger relief. This finding provides a new strategy to balance high strength and good damage tolerance property of metallic materials.
\end{abstract}

Keywords: fatigue, fracture, notch sensitivity, biomedical metal, titanium alloy

\section{INTRODUCTION}

Excellent corrosion resistance, good biocompatibility and low elastic modulus make titanium and its alloys fulfill the property requirements of biomedical field better than other competing materials such as stainless steels and Co$\mathrm{Cr}$ alloys [1]. Although commercial pure titanium and Ti$6 \mathrm{Al}-4 \mathrm{~V}$ alloy are most used for biomedical applications, there are still two remaining problems to be solved $[2,3]$. One is the potential toxicity of alloying elements, such as $\mathrm{V}$ ions released from Ti-6Al-4V alloy. Another is that their modulus $(\sim 110 \mathrm{GPa})$ is higher than that of bone tissues (less than $20 \mathrm{GPa}$ in general). The mismatch produces the so-called stress shielding, the origin of bone resorption and implant loosening. To overcome these limitations, some $\beta$-type titanium alloys containing nontoxic elements have been developed in recent years with the advantage of lower modulus [4-6]. However, the problem of stress shielding still exists and low modulus is usually achieved at the expense of high strength.

Ti-24Nb-4Zr-8Sn (abbreviated as Ti2448 from its chemical composition in weight percent) alloy is a multifunctional $\beta$-type titanium alloy developed for biomedical applications [7,8]. Its high strength $(\sim 850 \mathrm{MPa})$, low modulus ( $42 \mathrm{GPa})$ and good biocompatibility make it suitable to produce orthopedic implants. Investigations on its biological functions have shown that these implants made of the alloy improve new bone formation in marrow cavity [9-11]. The functional alloy is strong with a strength-to-modulus ratio $(\sigma / E)$ of $2 \%$ and possesses a good combination of stress-controlled high cycle and strain-controlled low cycle fatigue properties $[12,13]$. Since orthopedic implants consist of different kinds of notches in order to fix with bones effectively, it is necessary to investigate the notch fatigue property of the alloy and provide a reference for its long term service.

The previous investigations have shown that there exists an inverse strength and fatigue damage tolerance relationship, i.e., higher strength causes stronger fatigue notch sensitivity [14], faster fatigue crack growth rate [15] and worse fracture toughness [16]. Various strategies have been put forward to improve these balances. For

\footnotetext{
${ }^{1}$ Shenyang National Laboratory for Materials Science, Institute of Metal Research, Chinese Academy of Sciences, Shenyang 110016, China

${ }^{2}$ School of Materials Science and Engineering, University of Science and Technology of China, Shenyang 110016, China

* Corresponding author (email: ylhao@imr.ac.cn)
} 
examples, the nanoscale coherent interface via deformation twin increases strength significantly without severe loss of ductility [17], and some toughening mechanisms including crack deflection and crack-tip shielding impede fatigue crack growth [18]. Our recent investigations showed that Ti2448 contains a nanoscale spatial modulation of $\mathrm{Nb}$, which is created by the isostructural phase decomposition, and an in-situ elastically confined martensitic transformation was proposed to explain its novel nonlinear elasticity [19]. This leads to some unprecedented properties such as strong in strength, soft in modulus, ductile in toughness in combination with super-elasticity and entirely tunable thermal expansion from positive, via zero, to negative in a wide temperature range $[20,21]$. The nanoscale $\mathrm{Nb}$ modulation can stabilize the $\beta$ phase and cause a successive atomic rearrangement via the up-hill $\mathrm{Nb}$ diffusion $[22,23]$. Though the novel nonlinear elasticity induced by the nanoscale $\mathrm{Nb}$ modulation has been revealed recently, its effect on fatigue notch resistance of Ti2448 alloy is unclear.

In the present study, fatigue notch behavior of Ti2448 alloy was investigated by using the notched samples at room temperature. The results show that this is a fatigue notch tolerant alloy which breaks significantly the limit of the previous-reported metallic materials. This can be explained by an adaptive mechanism induced by the nonlinear elasticity.

\section{EXPERIMENTAL SECTION}

\section{Materials preparation}

Using a Ti-Sn master alloy and pure $\mathrm{Ti}, \mathrm{Nb}, \mathrm{Zr}$ as raw materials, a Ti2448 ingot with $380 \mathrm{~mm}$ in diameter was fabricated by vacuum arc melting. Chemical and gas analyses showed that the ingot has a composition of $24.2 \mathrm{Nb}, 3.76 \mathrm{Zr}, 8.08 \mathrm{Sn}$ and $0.11 \mathrm{O}$ (wt.\%). It was forged at $1123 \mathrm{~K}$ into a bar with $55 \mathrm{~mm}$ in diameter and then rolled at $1073 \mathrm{~K}$ into a bar with $12 \mathrm{~mm}$ in diameter. The asrolled alloy has a single $\beta$ phase microstructure with an average grain size of $\sim 5 \mu \mathrm{m}$ and sub-grain size of $\sim 0.6 \mu \mathrm{m}$ as well as a nanoscale $\mathrm{Nb}$ modulation with the domain size of 2-3 nm [20,24]. Three kinds of V-type circumferential notch specimens (Fig. 1) with stress concentration factor $\left(K_{\mathrm{t}}\right)$ of 2,3 and 4 were machined for fatigue tests [25]. For comparison on the fatigue fracture surfaces, notch samples $\left(K_{\mathrm{t}}=3\right)$ of Ti-6Al-4V alloy with equiaxed microstructure and tensile strength of $1020 \mathrm{MPa}$ were tested at $R=0.1$ as a representative of conventional metallic materials with linear elasticity.

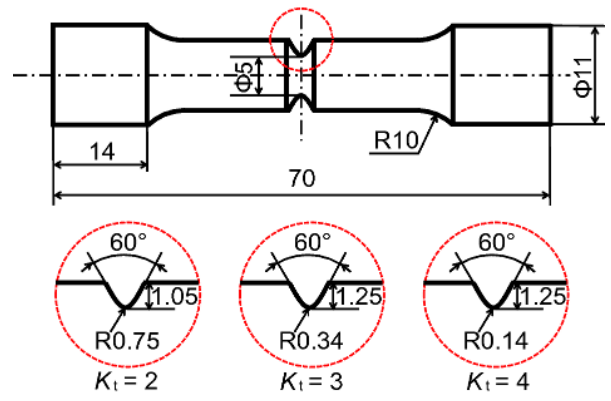

Figure 1 Geometry of V-type circumferentially notched specimen together with the enlarged details of notches.

\section{Fatigue test}

Constant stress amplitude fatigue tests were performed with Instron-8872 fatigue testing system under different stress ratio $(R=-1,0.1,0.3)$ at room temperature. Since titanium alloys have good corrosion resistance in physiological environment, our previous fatigue tests of Ti2448 in $0.9 \% \mathrm{NaCl}$ solution had little effect on its fatigue life [26]. Thus, the tests were conducted in air. Load configuration with sinusoidal waveform and frequency $f=$ $20 \mathrm{~Hz}$ were used. All specimens were polished mechanically in order to reduce the surface roughness before test. Fatigue limit was determined as the maximum stress below which fatigue failure did not occur after $10^{7}$ cycles. To confirm the accuracy, the fatigue limit was confirmed by the repeated tests of two specimens.

\section{Fracture surface and microstructure analysis}

Macro photograph and low magnification three dimensional (3D) profiles of fracture surfaces were observed by digital camera (DC) and KEYENCE VHX-2000 threedimensional optical microscopic (OM) system (Japan), respectively. Microscopic observation of fracture surfaces were conducted by a JSM-6301F field emission scanning electron microscope (SEM). Microstructure near notch roots was examined by a JEOL-2100 transmission electron microscopy (TEM, Japan) at $200 \mathrm{kV}$. TEM specimens were prepared from mechanically-thinned plates by twinjet electro-polishing in a solution of $21 \%$ per chloric acid, 50\% methanol and 29\% $n$-butyl alcohol at $\sim 250 \mathrm{~K}$.

\section{RESULTS}

\section{Notch fatigue properties}

The maximum nominal stress as a function of cycle numbers to failure $(S-N)$ curves of Ti2448 alloy with three notch configurations were measured. The results are plotted in Fig. 2 together with the previous data of 

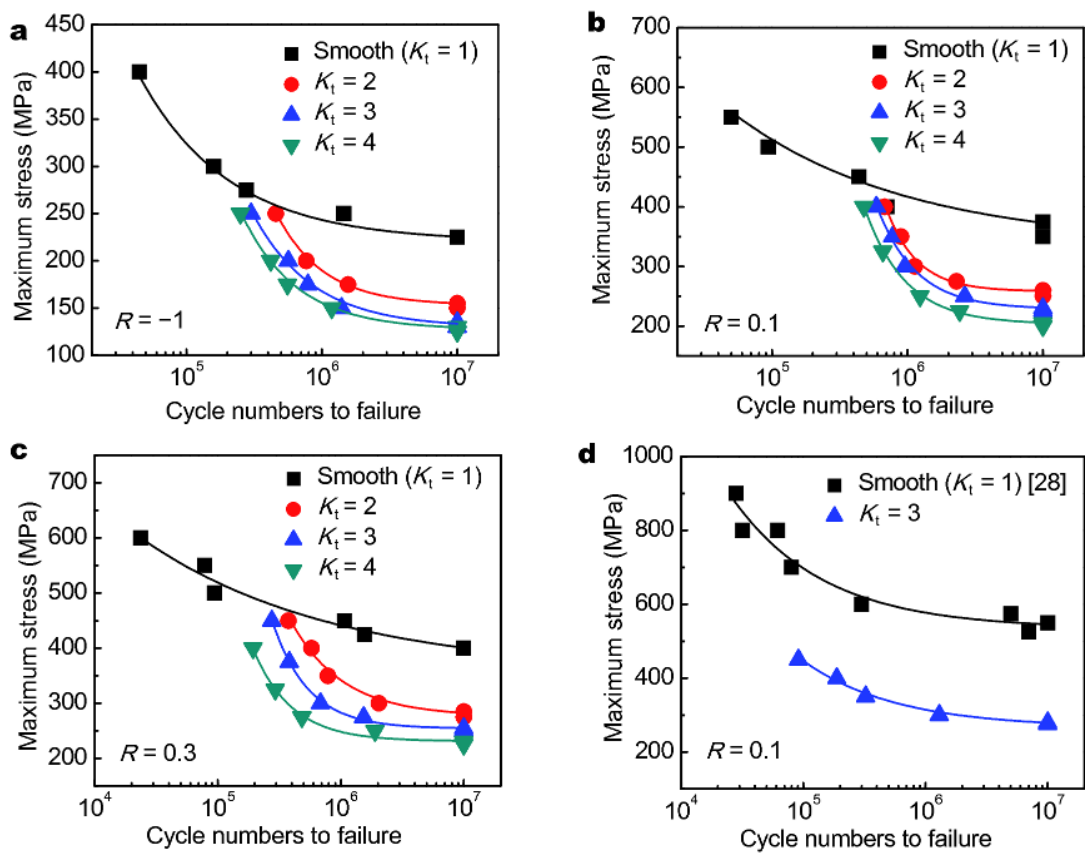

Figure 2 Fatigue $S-N$ curves of Ti2448 alloy with different notch configuration measured at $R=-1$ (a), $R=0.1$ (b) and $R=0.3$ (c), and Ti-6Al-4V alloy (d) (data were measured under $K_{\mathrm{t}}=3$ and $R=0.1$, while the data of smooth specimens are cited from Ref. [28]).

smooth specimens [12]. They show clearly that its fatigue limit decreases as the stress concentration factor $K_{\mathrm{t}}$ increases at the same stress ratio $R$ and increases with the increased $R$ at the same $K_{\mathrm{t}}$. Both are normal in tendency with the conventional metallic materials [27]. The $S-N$ curves of Ti-6Al-4V alloy are given in Fig. 2d, in which the data of smooth specimens are cited from ref. [28] due to their identical microstructure and mechanical properties.

From the listed data in Table 1, the fatigue notch sensitivity $(q)$ can be calculated by

$$
q=\left(K_{\mathrm{f}}-1\right) /\left(K_{\mathrm{t}}-1\right)
$$

where $K_{\mathrm{t}}$ is the theoretical stress concentration factor and $K_{\mathrm{f}}$ is fatigue notch factor and defined as:

$$
K_{\mathrm{f}}=\sigma_{\mathrm{c}, \text { smooth }} / \sigma_{\mathrm{c}, \text { notch }} \text {, }
$$

where $\sigma_{\mathrm{c}, \text { smooth }}$ and $\sigma_{\mathrm{c}, \text { notch }}$ are the fatigue limit of smooth and notch specimens respectively. The factor $q$ evaluates the notch sensitivity to fatigue and generally ranges between zero and unity. The larger value of $q$, the more

Table 1 Fatigue limit (MPa) of Ti2448 alloy with different notch configuration

\begin{tabular}{ccccc}
\hline Stress ratio & Smooth $\left(K_{\mathrm{t}}=1\right)[12]$ & $K_{\mathrm{t}}=2$ & $K_{\mathrm{t}}=3$ & $K_{\mathrm{t}}=4$ \\
\hline$R=-1$ & 225 & 155 & 135 & 130 \\
$R=0.1$ & 375 & 260 & 230 & 205 \\
$R=0.3$ & 400 & 285 & 255 & 230 \\
\hline
\end{tabular}

sensitive to notch fatigue. The calculated data by Equations 1 and 2 are presented in Fig. 3. They show that its $K_{\mathrm{f}}$ increases slowly as $K_{\mathrm{t}}$ increases, resulting in a decreased $q$ under the same $R$. The factor $q$ is small, below 0.5 for all the tests and only about 0.25 when $K_{\mathrm{t}}=4$, revealing that the alloy is notch insensitive to fatigue. Additionally, the factor $q$ has a weak dependence on stress ratio, as can be indicated by the similar $q$ at three different $R$ in Fig. 3 .

\section{Fatigue fracture surfaces}

3D profiles of fracture surfaces for Ti2448 alloy were analyzed by depth-assembly function of OM and a typical example is given in Fig. 4a together with the corresponding lateral macroscopic image. Both demonstrate an abnormal mountain-shape fracture surface with a height of $3.1 \mathrm{~mm}$, reaching $60 \%$ of the specimen root diameter of $5.0 \mathrm{~mm}$. Its crack growth path obviously deviated from the nominal crack extension plane, which is perpendicular to loading direction. This is in sharp contrast with other metallic materials such as Ti-6Al-4V alloy (Fig. 4b), which exhibits a normal straight and flat fracture surface with the maximum height only about $0.45 \mathrm{~mm}$. Evident difference in the aspect of fracture surface between Ti2448 and Ti-6Al-4V indicates that fatigue crack growth experienced a much longer and more tortuous extension path for Ti2448 alloy.

The abnormal macroscopic fatigue fracture behavior of 


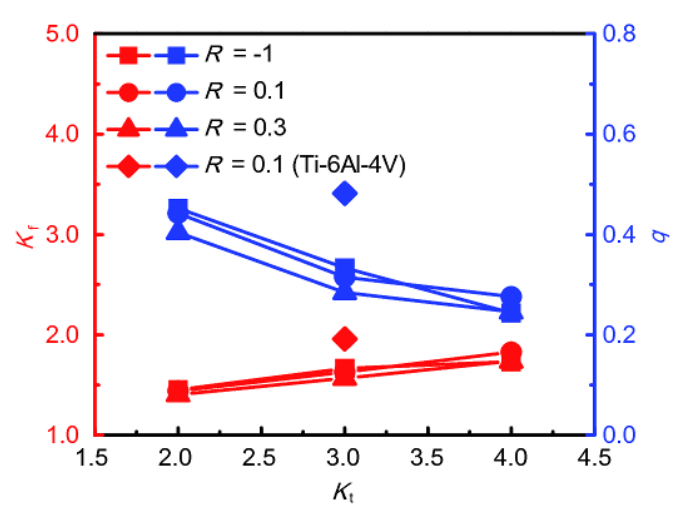

Figure 3 Fatigue notch factor $K_{\mathrm{f}}$ and fatigue notch sensitivity $q$ in dependence on $K_{\mathrm{t}}$ of Ti2 448 alloy. The data of Ti-6Al-4V alloy measured in Fig. $2 \mathrm{~d}$ was also presented.

Ti2448 prompts careful observation of microscopic fracture surface by SEM. Three fracture zones of Ti2448, i.e., crack initiation zone, crack growth zone and final fracture zone, can be distinguished (Fig. 5a). A circle-shaped crack initiation zone makes it hard to identify the main crack initiation site (Fig. 5b). Within crack growth region, typical tire-shape traces can be observed in accompany with plenty of secondary cracks (Fig. 5 c). The final fracture zone consists of many dimples with size of tens of micrometers (Fig. 5d), suggesting a ductile fracture mode. On the other hand, Ti-6Al-4V alloy exhibits a typical fracture surface of metallic materials (Fig. 6). Three fracture zones can be easily identified (Fig. 6a). The crack initiated from a single site of specimen edge (Fig. 6b). Fatigue striations and some secondary cracks can be observed (Fig. 6c), with the crack propagation direction from bottom to top. Dimples can also be detected within the final fracture region (Fig. 6d), which are merely smaller in size and shallower in depth than that observed in Ti2448.

\section{Microstructure near the notch root}

Fig. 7 shows the bright field TEM images of Ti2448 alloy before and after fatigue test, with their corresponding selected area diffraction (SAD) patterns at the top-left insets. They give a consistent conclusion with our previous study that the as hot-rolled specimen has a single $\beta$ phase before fatigue test (Fig. 7a) and stress-induced martensitic transformation from $\beta$ to $\alpha^{\prime \prime}$ was detected near the notch root after fatigue test (Fig. $7 b$ ) $[12,13]$. It should be noted that the volume fraction of $\alpha^{\prime \prime}$ martensite is tiny, as evidenced by the weak diffraction spots of $\alpha^{\prime \prime}$ (Fig. 7b). Unexpectedly, they exhibit a diffusion controlled plate-like morphology of a phase but possess or-

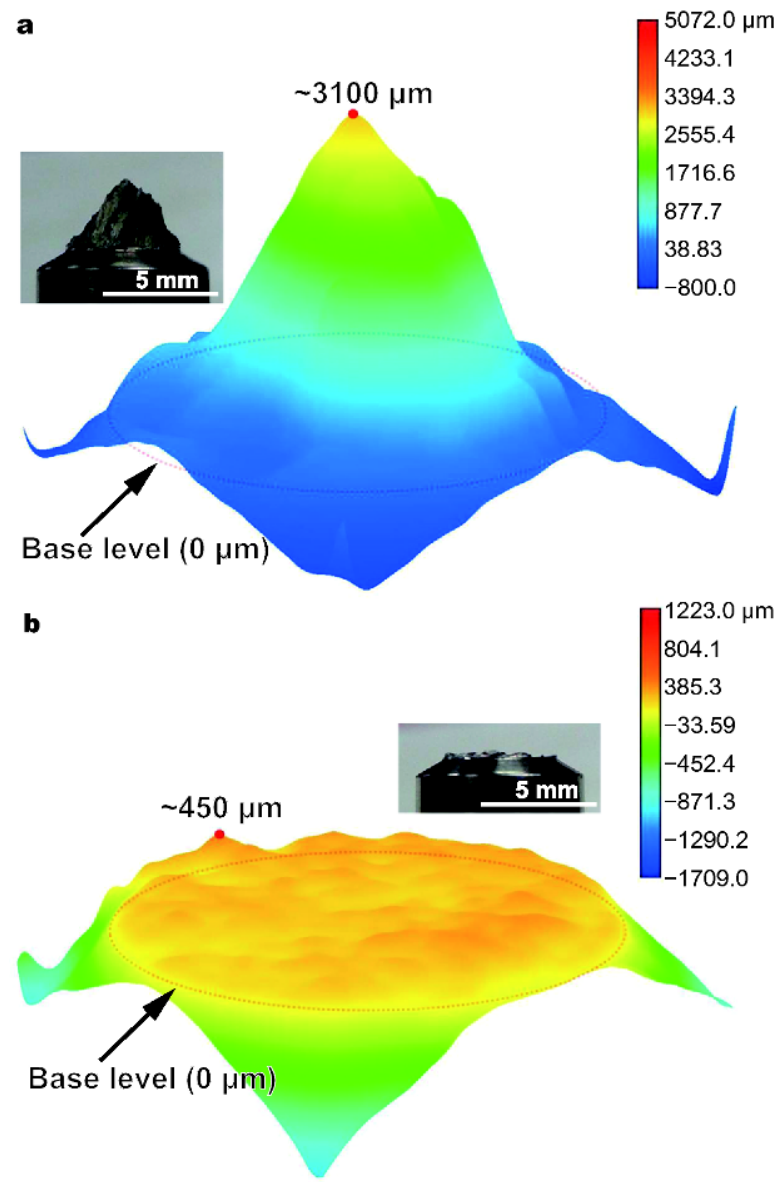

Figure 4 3D fracture surfaces of Ti2448 alloy $(N=954653)$ (a) and Ti$6 \mathrm{Al}-4 \mathrm{~V}$ alloy $(N=323408)(\mathrm{b})$ tested at $K_{\mathrm{t}}=3$ and $R=0.1$, with corresponding macroscopic photograph aside. (The dotted ellipse denotes the base level and the red solid point denotes the highest point of fracture surface).

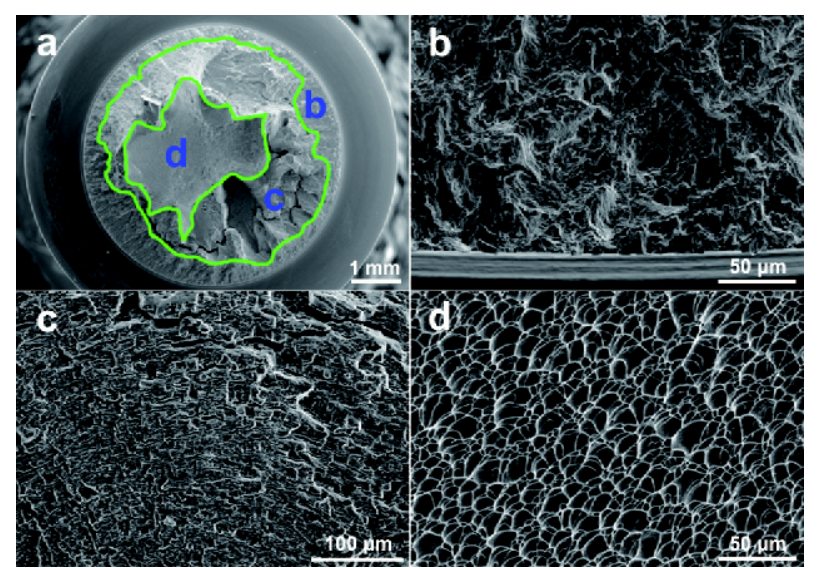

Figure 5 SEM images of fracture surface for Ti2448 alloy tested at $K_{\mathrm{t}}=4$ and $R=0.1$ ( $N=656785)$. (a) Overall morphology with green solid lines picking out three different fracture zones, (b) crack initiation zone, (c) crack propagation zone and (d) final rupture zone. 


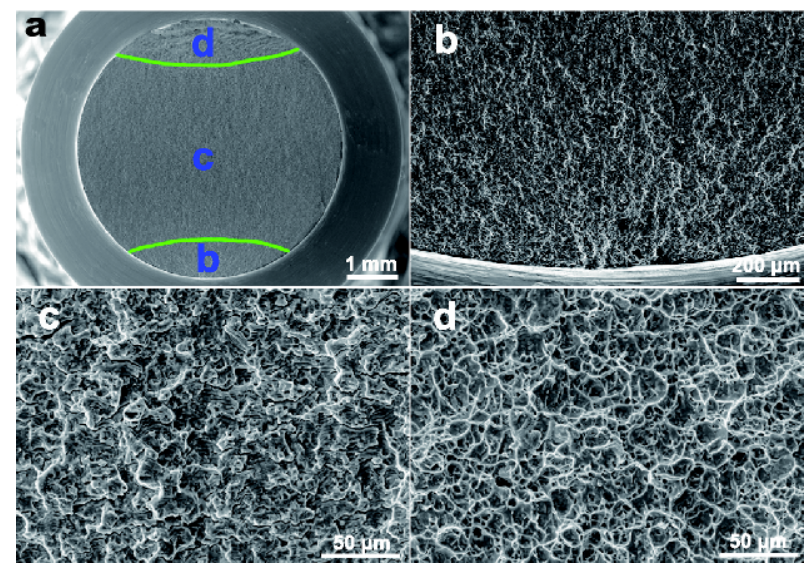

Figure 6 SEM images of fracture surface for Ti-6Al-4V alloy tested at $K_{\mathrm{t}}=3$ and $R=0.1 \quad(N=187814)$. (a) Overall morphology with green solid lines picking out three different fracture zones, (b) crack initiation zone, (c) crack propagation zone and (d) final rupture zone.
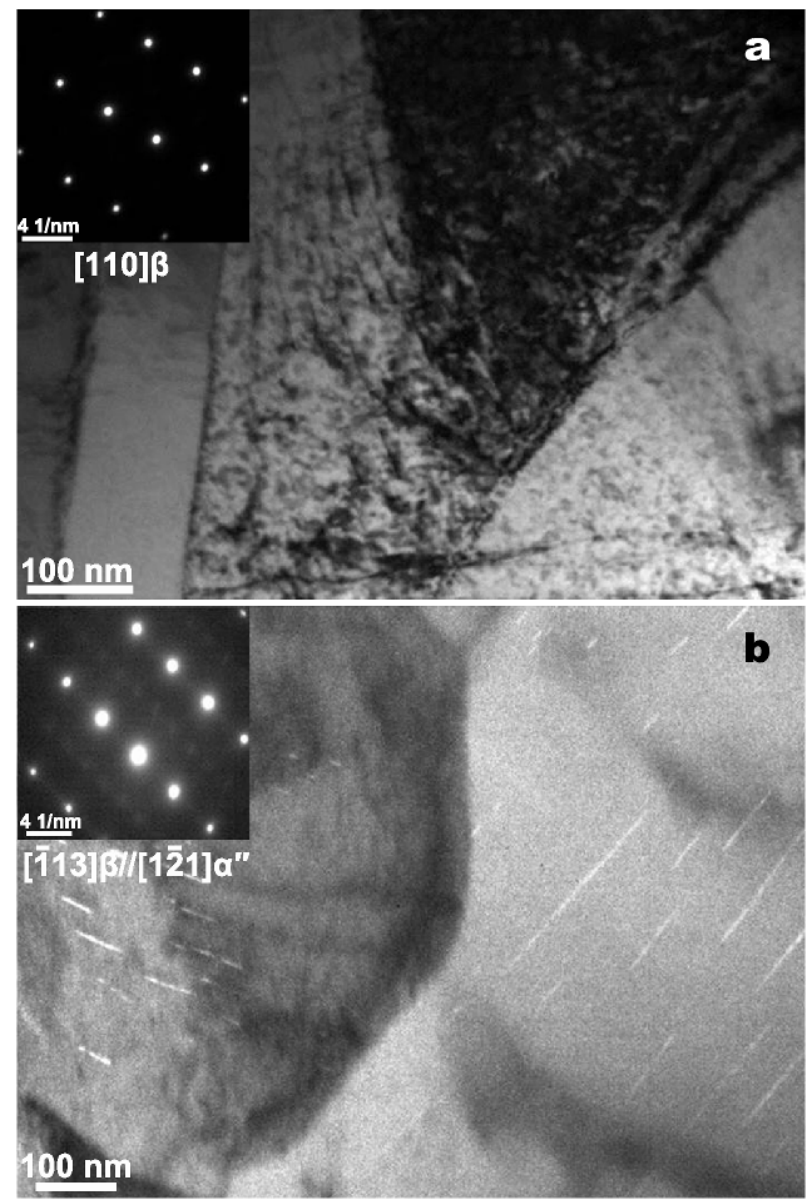

Figure 7 Bright field TEM microstructure of Ti2448 alloy $\left(K_{\mathrm{t}}=4\right.$ specimen tested at $R=0.1$ and without failure after $10^{7}$ cycles) before (a) and after (b) fatigue test, with corresponding SAD patterns at the top-left corner.

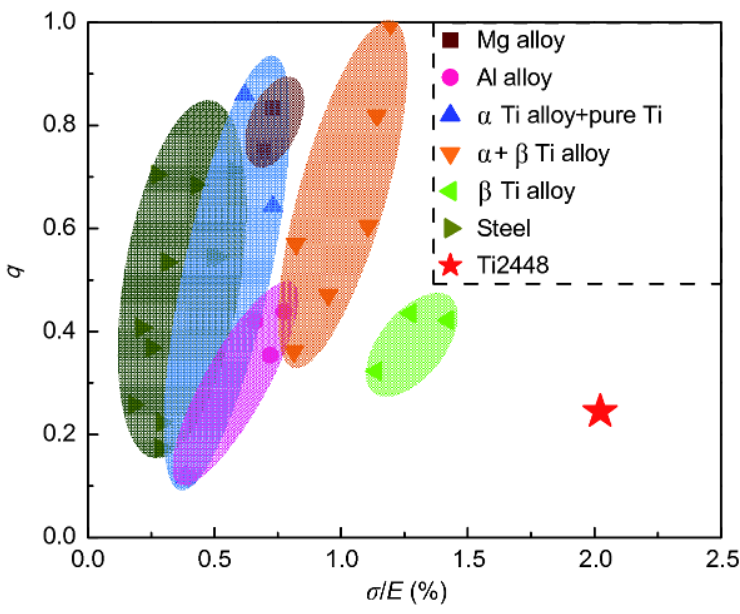

Figure 8 Comparing fatigue notch sensitivity and strength-modulus ratio of Ti2448 alloy with other metallic materials, including $\mathrm{Mg}$ alloys [30], Al alloys [31-33], Ti alloys [27,29,34-38] and steels [14,39-42].

thorhombic symmetry of $\alpha^{\prime \prime}$ martensite (Fig. 7b). These are similar with the orthorhombic phase produced by the up-hill diffusion of the Nb-lean domains as the decomposition is enhanced by heat treatment [22].

\section{DISCUSSION}

\section{Comparison of fatigue notch properties with other metallic} materials

The study demonstrates that multifunctional Ti2448 alloy is strong with a high $\sigma / E$ ratio being identical with amorphous materials [19] but tolerant to fatigue notch damage (Fig. 3). The unexpected combination is presented in Fig. 8 for a comparison with other metallic materials, such as $\mathrm{Mg}$ alloys, $\mathrm{Al}$ alloys, $\mathrm{Ti}$ alloys and steels, under the condition of stress concentration factor of 4 .

It should be noted that the fatigue notch sensitivity $q$ is variable with both $K_{\mathrm{t}}$ and $R$. Since these selected data under $R=-1$ in refs. [14,27,29-42] were measured with different $K_{\mathrm{t}}$, the $q$ under the identical condition of $K_{\mathrm{t}}=4$ (Fig. 8) has to be calculated by the Kuhn-Hardrath equation [25]:

$$
q=1 /(1+\sqrt{\rho / r})
$$

where $\rho$ is a material constant which can be determined by fitting these measured $(q, r)$ data. Thus, the $q$ is calculated by inputting the corresponding $r$ of $K_{\mathrm{t}}=4$, which is obtained from stress concentration factor manual.

The comparison on $\sigma / E$ and $q$ of several materials in Fig. 8 reveals three points. First, Ti2448 alloy is strong but tolerant to fatigue notch damage, which exceeds significantly the limit of other materials. Second, the low 


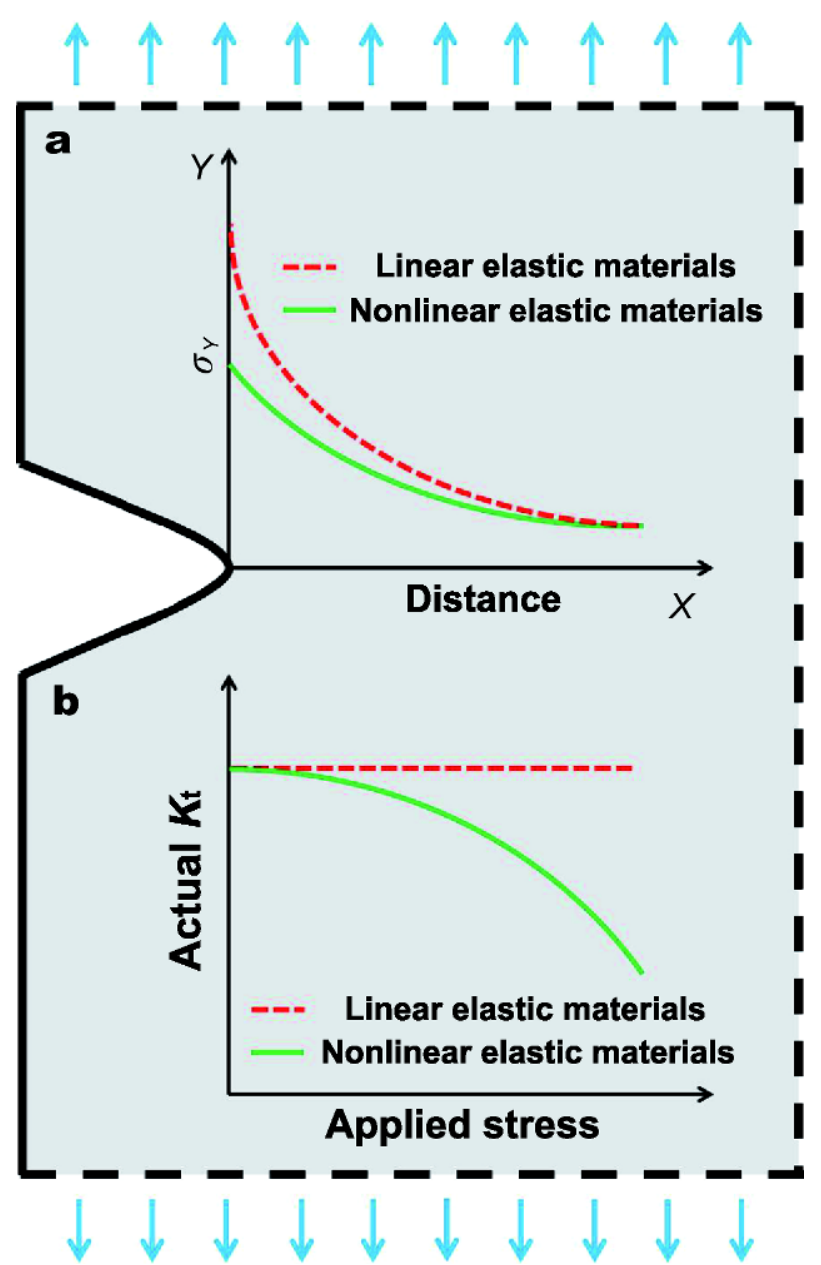

Figure 9 Schematic to show the effect of elastic deformation behavior on stress concentration. (a) The vertical stress in dependence on horizontal distance to notch tip; (b) the relationship between actual $K_{\mathrm{t}}$ and applied stress.

modulus $\beta$ type biomedical titanium alloys are potential for load-bearing applications to ensure long-term service safety because they are tolerant to notch, as evidenced by the decreased $q$ of the $\alpha,(\alpha+\beta)$ and $\beta$ type alloys under the identical $\sigma / E$ ratio. Lastly, titanium alloys, in particular of the $(\alpha+\beta)$ and $\beta$ types, is more tolerant than steels under the identical $\sigma / E$ ratio. This is in sharp contrast with the generally accepted viewpoint that titanium alloys, especially $(\alpha+\beta)$ type alloys, are more sensitive to notch $[27,40]$.

\section{Weak fatigue notch sensitivity of Ti2448 alloy}

Fatigue failure lifetime consists of two parts, i.e., the crack initiation and its propagation. To reveal the origin of strength but tolerance to notch damage, both are analyzed respectively in comparison with these materials exhibiting the typical linear elasticity.

The fatigue fracture surface observations (Figs 4 and 5) show that the crack experiences a much more deflected and tortuous extension path than that of Ti-6Al-4V alloy. This is obvious to reduce the effective driving force of crack tip $[43,44]$, resulting in a lower crack growth rate as compared to the straight crack. Thus the large scale nonflat crack in Fig. 4a can hinder its propagation effectively and extend the crack growth life. Since it is generally accepted that the crack growth does not contribute to a main portion of the total life in high cycle fatigue of linear elastic materials, the weak fatigue notch damage would be attributed to the resistance mechanism on fatigue crack initiation. Here we show that the nonlinear elasticity makes a significant contribution.

A mechanical constitutive model has been established to evaluate the nonlinear elastic materials (NLEM) [4547]. As shown schematically in Fig. 9, the simulations reveal that the nonlinear elasticity can modify the stress distribution and its concentration factor near the notch tip as compared with the linear elastic materials (LEM) [48]. The upper curves (Fig. 9a) show more smooth stress distribution in the NLEM while the below curves (Fig. 9b) demonstrate that the concentration factor decreases gradually as the applied stress increases in the NLEM but keeps constant in the LEM. The latter suggests that the actual stress concentration felt by the notch roots of NLEM is less than that calculated from the linear elasticity theory, especially in the case of high stress level. This is an adaptive damage resistant way of the higher applied stress and the stronger stress relief to ease its concentration at the root, resulting in weaker notch sensitivity and longer crack initiation lifetime.

\section{CONCLUSIONS}

This work focuses on the fatigue notch damage of Ti2448 alloy possessing a nonlinear elasticity via a comparison with the typical biomedical Ti-6Al-4V alloy exhibiting the normal linear elasticity. The main results are summarized as follows. (1) Contributing by the nonlinear elasticity, Ti2448 alloy has a good combination of high strength and strong fatigue notch resistance, which exceeds significantly the limit of other linear elastic metallic materials. (2) The alloy demonstrates a kind of extremely deflected and mountain-shape fracture surface, leading to a much longer and more tortuous extension path than that of Ti-6Al-4V alloy. (3) Weak fatigue notch sensitivity of this alloy may be mainly attributed to its nonlinear elasticity caused by the nanoscale $\mathrm{Nb}$ modulation, which 
can relief the stress concentration of notch root. (4) The findings together with the simulations of the NLEM provide a new strategy to improve fatigue damage tolerance of metallic materials.

Received 20 September 2017; accepted 9 November 2017; published online 20 December 2017

1 Brunette DM, Tengvall $\mathrm{P}$, Textor M, et al. Titanium in Medicine. Berlin: Springer, 2001

2 Long M, Rack HJ. Titanium alloys in total joint replacement-a materials science perspective. Biomaterials, 1998, 19: 1621-1639

3 Li S, Li X, Hou W, et al. Fabrication of open-cellular (porous) titanium alloy implants: osseointegration, vascularization and preliminary human trials. Sci China Mater, 2018, 61: 525-536

4 Saito T, Furuta T, Hwang JH, et al. Multifunctional alloys obtained via a dislocation-free plastic deformation mechanism. Science, 2003, 300: 464-467

5 Geetha M, Singh AK, Asokamani R, et al. Ti based biomaterials, the ultimate choice for orthopaedic implants-a review. Prog Mater Sci, 2009, 54: 397-425

6 Niinomi M. Recent metallic materials for biomedical applications. Metall Mat Trans A, 2002, 33: 477-486

7 Hao YL, Li SJ, Sun SY, et al. Super-elastic titanium alloy with unstable plastic deformation. Appl Phys Lett, 2005, 87: 091906

8 Hao YL, Li SJ, Sun BB, et al. Ductile titanium alloy with low poisson's ratio. Phys Rev Lett, 2007, 98: 216405

9 Guo Z, Fu J, Zhang YQ, et al. Early effect of Ti-24Nb-4Zr-7.9Sn intramedullary nails on fractured bone. Mater Sci Eng-C, 2009, 29: 963-968

10 Nune KC, Misra RDK, Li SJ, et al. Cellular response of osteoblasts to low modulus $\mathrm{Ti}-24 \mathrm{Nb}-4 \mathrm{Zr}-8 \mathrm{Sn}$ alloy mesh structure. J Biomed Mater Res, 2017, 105: 859-870

11 Nune KC, Misra RDK, Li SJ, et al. Osteoblast cellular activity on low elastic modulus Ti-24Nb-4Zr-8Sn alloy. Dental Mater, 2017, 33: $152-165$

12 Zhang SQ, Li SJ, Jia MT, et al. Fatigue properties of a multifunctional titanium alloy exhibiting nonlinear elastic deformation behavior. Scr Mater, 2009, 60: 733-736

13 Zhang SQ, Li SJ, Jia MT, et al. Low-cycle fatigue properties of a titanium alloy exhibiting nonlinear elastic deformation behavior. Acta Mater, 2011, 59: 4690-4699

14 Chapetti M, Katsura N, Tagawa T, et al. Static strengthening and fatigue blunt-notch sensitivity in low-carbon steels. Int J Fatigue, 2001, 23: 207-214

15 Xue $\mathrm{P}$, Huang Z, Wang B, et al. Intrinsic high cycle fatigue behavior of ultrafine grained pure $\mathrm{Cu}$ with stable structure. Sci China Mater, 2016, 59: 531-537

16 Cui L, Sun L, Zeng R, et al. In vitro degradation and biocompatibility of Mg-Li-Ca alloys-the influence of Li content. Sci China Mater, 2018, 61: 607-618

$17 \mathrm{Lu} \mathrm{K}, \mathrm{Lu} \mathrm{L}$, Suresh S. Strengthening materials by engineering coherent internal boundaries at the nanoscale. Science, 2009, 324: 349-352

18 Ritchie RO. Mechanisms of fatigue-crack propagation in ductile and brittle solids. Int J Fract, 1999, 100: 55-83

19 Wang HL. Continuous solid-state phase transformation in Ti2448 alloy over wide temperature range. Dissertation for Doctoral Degree. Shenyang: Institute of Metal Research, Chinese Academy of
Sciences, 2016

20 Hao YL, Wang HL, Li T, et al. Superelasticity and tunable thermal expansion across a wide temperature range. J Mater Sci Tech, 2016, 32: 705-709

21 Wang HL, Hao YL, He SY, et al. Elastically confined martensitic transformation at the nano-scale in a multifunctional titanium alloy. Acta Mater, 2017, 135: 330-339

22 Wang HL, Hao YL, He SY, et al. Tracing the coupled atomic shear and shuffle for a cubic to a hexagonal crystal transition. Scr Mater, 2017, 133: 70-74

23 Wang HL, Shah SAA, Hao YL, et al. Stabilizing the body centered cubic crystal in titanium alloys by a nano-scale concentration modulation. J Alloys Compd, 2017, 700: 155-158

24 Hao YL, Li SJ, Sun SY, et al. Elastic deformation behaviour of Ti24Nb-4Zr-7.9Sn for biomedical applications. Acta Biomater, 2007, 3: $277-286$

25 Pilkey WD, Pilkey DF. Peterson's Stress Concentration Factors. Hoboken: Wiley, 2008

26 Li SJ, Cui TC, Hao YL, et al. Fatigue properties of a metastable $\beta$ type titanium alloy with reversible phase transformation. Acta Biomater, 2008, 4: 305-317

27 Lanning D, Nicholas T, Haritos GK. On the use of critical distance theories for the prediction of the high cycle fatigue limit stress in notched Ti-6Al-4V. Int J Fatigue, 2005, 27: 45-57

28 Nalla RK, Boyce BL, Campbell JP, et al. Influence of microstructure on high-cycle fatigue of Ti-6Al-4V: bimodal $v s$. lamellar structures. Metall Mat Trans A, 2002, 33: 899-918

29 Haritos G, Nicholas T, Lanning DB. Notch size effects in HCF behavior of Ti-6Al-4V. Int J Fatigue, 1999, 21: 643-652

30 Liu WC, Dong J, Zhang P, et al. Smooth and notched fatigue performance of aging treated and shot peened ZK60 magnesium alloy. J Mater Res, 2010, 25: 1375-1387

31 Bian JC, Tokaji K, Ogawa T. Notch sensitivity of aluminum-lithium alloys in fatigue. Fat Frac Eng Mat Struct, 1995, 18: 119-127

32 Tokaji K. Notch fatigue behaviour in a Sb-modified permanentmold cast A356-T6 aluminium alloy. Mater Sci Eng-A, 2005, 396: 333-340

33 Benedetti M, Fontanari V, Santus C, et al. Notch fatigue behaviour of shot peened high-strength aluminium alloys: experiments and predictions using a critical distance method. Int J Fatigue, 2010, 32: 1600-1611

34 Kim WJ, Hyun CY, Kim HK. Fatigue strength of ultrafine-grained pure Ti after severe plastic deformation. Scr Mater, 2006, 54: 17451750

35 Yuri T, Ono Y, Ogata T. Effects of surface roughness and notch on fatigue properties for Ti-5Al-2.5Sn ELI alloy at cryogenic temperatures. Sci Tech Adv Mater, 2003, 4: 291-299

36 Yue T, Tabeshfar K, Forsyth PJE. Effect of microstructure on the plain and notched fatigue properties of IMI $550 \mathrm{Ti}$ alloy. Int J Fatigue, 1985, 7: 149-153

37 Baragetti S, Lusvarghi L, Pighetti Mantini F, et al. Fatigue behaviour of notched PVD-coated titanium components. Key Eng Mater, 2007, 348-349: 313-316

38 Akahori $\mathrm{T}$, Niinomi M, Otani $\mathrm{M}$, et al. Notch fatigue properties of a Ti-29Nb-13Ta-4.6Zr alloy for biomedical applications. J Jpn Inst Light Met, 2005, 55: 575-581

39 Khan MK, Liu YJ, Wang QY, et al. Effect of small scale notches on the very high cycle fatigue of AISI 310 stainless steel. Fatigue Fract Eng Mater Struct, 2015, 38: 290-299

40 Akita M, Tokaji K. Effect of carburizing on notch fatigue behaviour 
in AISI 316 austenitic stainless steel. Surf Coatings Tech, 2006, 200: 6073-6078

41 Chapetti MD, Miyata H, Tagawa T, et al. Fatigue strength of ultrafine grained steels. Mater Sci Eng-A, 2004, 381: 331-336

42 Hui W, Zhang Y, Zhao X, et al. High cycle fatigue behavior of Vmicroalloyed medium carbon steels: a comparison between bainitic and ferritic-pearlitic microstructures. Int J Fatigue, 2016, 91: 232241

43 Suresh S. Crack deflection: implications for the growth of long and short fatigue cracks. Metall Mater Trans A, 1983, 14: 2375-2385

44 Suresh S. Fatigue crack deflection and fracture surface contact: micromechanical models. Metall Mater Trans A, 1985, 16: 249-260

45 Rajagopal KR. On implicit constitutive theories. Appl Math, 2003, 48: 279-319

46 Rajagopal KR. The elasticity of elasticity. Zeit Angew Math Phys, 2007, 58: 309-317

47 Rajagopal KR. On the nonlinear elastic response of bodies in the small strain range. Acta Mech, 2014, 225: 1545-1553
Devendiran VK, Sandeep RK, Kannan K, et al. A thermodynamically consistent constitutive equation for describing the response exhibited by several alloys and the study of a meaningful physical problem. Int J Solids Struct, 2017, 108: 1-10

Acknowledgements This work was supported by the National Key Research and Development Program of China (2016YFC1102601 and 2017YFC1104901), the National Natural Science Foundation of China (51571190 and 51631007), and the Key Research Program of Frontier Sciences of Chinese Academy of Sciences (QYZDJ-SSW-JSC031).

Author contributions Hao Y designed the experiment. Zhang J, Shah SAA and Li S carried out the fatigue test, fracture surface observation and microstructure analysis. Zhang J and Hao Y wrote this paper. The project was supervised by Hao Y and Yang R. All authors contributed to the discussion.

Conflict of interest The authors declare that they have no conflict of interest.

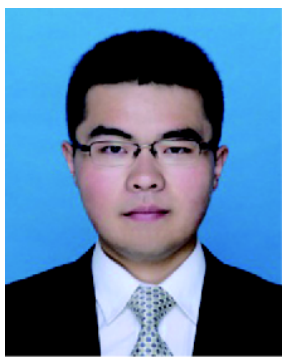

Jinrui Zhang received his BE degree from the University of Science and Technology Beijing in 2013 and is now a PhD student at the Institute of Metal Research, Chinese Academy of Sciences. His research interests include the damage tolerance of biomedical titanium alloy.

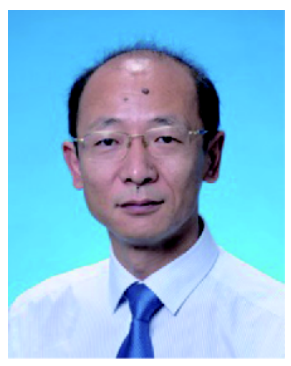

Yulin Hao is a professor at the Institute of Metal Research, Chinese Academy of Sciences. He received his PhD degree from the Institute of Metal Research, Chinese Academy of Sciences, in 1999. His research interests include the biomedical titanium alloys and their additive manufacturing.

\section{非线弹性医用钛合金的抗疲劳缺口损伤行为研究}

张金睿 ${ }^{1,2}$, Syed A. A. Shah ${ }^{1}$, 郝玉琳 ${ }^{*}$, 李述军 ${ }^{1}$, 杨锐 $^{1}$

摘要 金属材料的抗损伤容限能力一般随着强度的提高及模量的降低而显著弱化. 对于高强度低模量医用钛合金, 这可能引发长期使用 安全性的担忧. 本文以 Ti-24Nb-4Zr-8Sn合金为模型材料研究了缺口疲劳行为, 结果表明: 非线性弹性合金具有优异的抗疲劳缺口损伤能 力, 其强度与模量的比值高达 $2 \%$ 时仍然具有较弱的疲劳缺口敏感性, 两者关系远优于常规线弹性金属材料, 如不锈钢、钛合金、铝合金和 镁合金等; 该合金的疲劳断口呈现极度偏折的山峰状形貌, 显著抑制了裂纹的萌生与扩展. 依据非线性弹性变形理论, 本文给出了一种抑 制缺口疲劳损伤的自适应机制: 非线性弹性有效缓解了缺口根部的应力集中, 并且这种效果随着应力的提高而显著增强. 因此, 非线性弹 性变形行为是一种实现高强度金属材料耐疲劳损伤的重要手段. 